\title{
Transverse Load and Temperature Sensing Using Multiplexed Long-Period Fiber Gratings
}

\author{
Ismael Torres-Gómez ${ }^{1, * \mathbb{C}}$, Alejandro Martínez-Rios ${ }^{1}$, Gilberto Anzueto-Sánchez ${ }^{1}$, Daniel. E. Ceballos-Herrera ${ }^{2}$ \\ and Guillermo Salceda-Delgado ${ }^{3}$ \\ 1 Centro de Investigaciones en Óptica AC (CIO), Loma del Bosque 115, Lomas del Campestre, Leon, \\ Guanajuato 37150, Mexico; amr6@cio.mx (A.M.-R.); gilberto.anzueto@cio.mx (G.A.-S.) \\ 2 Instituto de Ingeniería, Universidad Nacional Autónoma de México (UNAM), Ciudad Universitaria, \\ Alcaldía Coyoacán, Mexico City 04510, Mexico; DCeballosH@iingen.unam.mx \\ 3 Facultad de Ciencias Físico Matemáticas, Universidad Autónoma de Nuevo León (UANL), \\ Avenida Universidad S/N, San Nicolás de los Garza, Nuevo León 66455, Mexico; \\ guillermo.salcedadl@uanl.edu.mx \\ * Correspondence: itorres@cio.mx
}

check for updates

Citation: Torres-Gómez, I.; MartínezRios, A.; Anzueto-Sánchez, G.; CeballosHerrera, D.E.; Salceda-Delgado, G. Transverse Load and Temperature Sensing Using Multiplexed Long-Period Fiber Gratings. Photonics 2021, 8, 1 .

https://dx.doi.org/10.3390/photonics8 010001

Received: 30 October 2020

Accepted: 16 December 2020

Published: 22 December 2020

Publisher's Note: MDPI stays neutral with regard to jurisdictional claims in published maps and institutional affiliations.

Copyright: () 2020 by the authors. Licensee MDPI, Basel, Switzerland. This article is an open access article distributed under the terms and conditions of the Creative Commons Attribution (CC BY) license (https: / / creativecommons.org/ licenses/by/4.0/).

\begin{abstract}
The simultaneous measurement of transverse load and temperature using two longperiod fiber gratings multiplexed in the wavelength domain is presented experimentally. For this, a mechanically induced long-period fiber grating (MI-LPFG) and a long-period fiber grating inscribed by a continuous-wave $\mathrm{CO}_{2}$ laser $\left(\mathrm{CO}_{2} \mathrm{LPFG}\right)$ are connected in cascade. First, the transverse load and the temperature measurements were individually performed by the multiplexed long-period fiber gratings configuration. The MI-LPFG is subject to a transverse load variation from 0-2000 $\mathrm{g}$ with steps of $500 \mathrm{~g}$, whereas the $\mathrm{CO}_{2}$ LPFG is unloaded and they are kept at room temperature. Similarly, the $\mathrm{CO}_{2}$ LPFG is subject to a temperature variation from 30 to $110{ }^{\circ} \mathrm{C}$ by increments of $20^{\circ} \mathrm{C}$, while the MI-LPFG with a constant transverse load of $2000 \mathrm{~g}$ is kept at room temperature. Subsequently, the simultaneous measurement of the transverse load and the temperature is performed by the multiplexed long-period fiber grating following the steps outlined above. According to the experimental results, the transverse load and temperature measurement present high repeatability for the individual and simultaneous process. Moreover, the multiplexed LPFGs exhibit low claddingmode crosstalk of transverse load and temperature. The coarse wavelength-division multiplexing (CWDM) of long-period fiber gratings is an attractive alternative technique in optical fiber distributed sensing applications.
\end{abstract}

Keywords: transverse load sensor; temperature sensor; long-period fiber gratings; primary rejection band; coarse wavelength-division multiplexing; optical fiber distributed sensing

\section{Introduction}

Long-period fiber gratings (LPFGs) are versatile components widely studied with relevant applications in telecommunications, fiber-optic lasers, and sensing systems [1-3]. Concerning sensing applications, LPFGs offer high sensitivity to external perturbations of the surrounding medium, immunity to electromagnetic fields, passive measurements, fast response, low insertion loss, small backscattering, compactness, and remote monitoring. These properties make LPFGs very attractive in developing physical, chemical, and biological fiber optic sensors [4-6]. Currently, several methods have been reported to produce LPFGs, such as exposure to ultra-violet (UV), electric arc discharge, $\mathrm{CO}_{2}$ laser radiation, femtosecond laser radiation, mechanical pressure, hydrogen-oxygen flame heating, and ion implementation, among others [7-13]. Despite the progress made in the fabrication methods of LPFGs, there are still some challenges to harnessing the potential of LPFGs in sensing applications, such as the development of low-cost interrogation systems [14] and 
the optical fiber distributed sensing applications by the wavelength-division multiplexing of LPFGs in cascade.

Two different approaches have been reported for the optical fiber distributed sensing applications with wavelength-division multiplexing of LPFGs. The first method uses two similar concatenated LPFGs to conform a Mach-Zehnder interferometer [15]. In this way, one can have two or more Mach-Zehnder interferometers with distinct cavity lengths in series to measure different parameters simultaneously [16,17]. However, interferometric optical fiber sensors produce differential outputs. Therefore, they require complex demodulation techniques such as filtering the carrier frequencies in the frequency domain and the unwrapped phase processes to extract the external perturbations [18]. The second method entails implementing two or more different LPFGs in series in such form that their reference rejection bands do not overlap and operate independently [19-22]. Although these schemes require simple demodulation techniques, the wavelength-division multiplexing of LPFGs is delimited because LPFGs usually generate multiple rejection bands. However, mechanically induced long-period fiber gratings (MI-LPFGs) with a primary rejection band have recently been reported using laminated plates [23]. Such MI-LPFGs with a principal rejection band facilitate the use of the CWDM technique for LPFG sensors in cascade.

In this report, we demonstrate experimentally the simultaneous measurement of transverse load and temperature using two multiplexed long-period fiber gratings. For this, an MI-LPFG is connected with a $\mathrm{CO}_{2}$ LPFG in cascade to measure transverse load and temperature, respectively. These LPFGs are notable for having a prominent attenuation band over a wide wavelength range. As far as we know, this is the first time that the technique of wavelength-division multiplexing using LPFGs with a prominent attenuation band is presented. The work's structure comprises the following sections: Section 1 explains an antecedent on the two approaches of the multiplexing LPFGs reported previously, highlighting their scope and limitations. The relevance of the wavelength-division multiplexing technique using LPFGs with a prominent attenuation band and their application in distributed sensing is also presented. The general principle of the phase-matching in LPFGs is described in Section 2. Section 3 describes the experimental arrangement and its principal features. Also, it describes in detail the implementation of the MI-LPFG and the inscription of the $\mathrm{CO}_{2}$ LPFG. In Section 4, the individual characterization of the MI-LPFG and the $\mathrm{CO}_{2}$ LPFG is presented when the LPFGs are under transverse load and temperature, respectively. Also, we show the simultaneous measurement of transverse load and temperature. Finally, Section 5 presents the most relevant findings of the work.

\section{LPFGs Principle}

Long-period fiber gratings result from a periodic refractive index modulation produced in the core of a single-mode optical fiber. The long-period fiber gratings operate as modal couplers allowing the light transfer from the fundamental mode in the core $\left(\mathrm{LP}_{01}\right)$ to different co-propagating high-order cladding modes $\left(\mathrm{LP}_{0 \mathrm{~m}}, \mathrm{~m}=2,3,4 \ldots\right)$. This coupling results in a discrete set of rejection bands in the grating transmission spectrum due to the scattering of the high-order cladding modes at the interface between the cladding and the external medium. Where the resonant central wavelength $\left(\lambda_{\mathrm{m}}\right)$ of the individual rejection bands must fulfill the phase-matching condition [7],

$$
\lambda_{\mathrm{m}}=\left(\mathrm{n}_{01}-\mathrm{n}_{0 \mathrm{~m}}\right) \Lambda
$$

where $\mathrm{n}_{01}$ and $\mathrm{n}_{0 \mathrm{~m}}$ represent the effective refractive indices of the $\mathrm{LP}_{01}$ mode in the core and the $\mathrm{LP}_{0 \mathrm{~m}}$ mode in the cladding, respectively, and $\Lambda$ is the period of the refractive index modulation in the long-period fiber grating.

The number of rejection bands in an LPFG depends upon the structure and material composition of the host single-mode optical fiber and the corresponding refractive index modulation. In general, LPFGs in single-modal optical fiber with a cosinusoidal refractive index modulation and a typical period from 100-600 $\mu \mathrm{m}$, usually present spectrum transmissions with three to five rejection bands in the spectral range from 1200-1700 nm [7], 
where the attenuation depth of the rejection bands typically is more profound as the coupling mode's order of the cladding increases. LPFGs with this number of the rejection bands and their spectral side lobes limit the wavelength-division multiplexing of LPFGs in cascade [16]. However, in the last years, it has been shown that LPFGs with a primary rejection band over a wide wavelength range using different inscription techniques is feasible [23-27]. Long-period fiber gratings with a primary rejection band facilitate the deployment of fiber optic distributed sensing systems based on the wavelength-division multiplexing of LPFGs.

\section{Setup and Components}

Figure 1a illustrates the experimental configuration schematic for measuring the transverse load (TL) and the temperature (T) by the multiplexed LPFGs. The experimental setup consisted of an MI-LPFG connected to a $\mathrm{CO}_{2}$ LPFG in cascade. The $\mathrm{CO}_{2} \mathrm{LPFG}$ was located over an electric hot plate where the temperature can be manually controlled. The input end of the MI-LPFG was connected to a white light source (WLS; AQ-4303B), and the output end of the $\mathrm{CO}_{2}$ LPFG was connected to an optical spectrum analyzer (OSA; AQ-6315A). For each proof, the transmission spectrum of the cascaded LPFGs was recorded by the optical spectrum analyzer, while the spectral resolution was set to $1 \mathrm{~nm}$. The fiber used in the double grating configuration is a standard single-mode fiber (SMF-28) for telecommunications. The LPFGs were separated $10 \mathrm{~cm}$ in the single-mode optical fiber. Figure $1 \mathrm{~b}$ illustrates the photography of the experimental configuration.
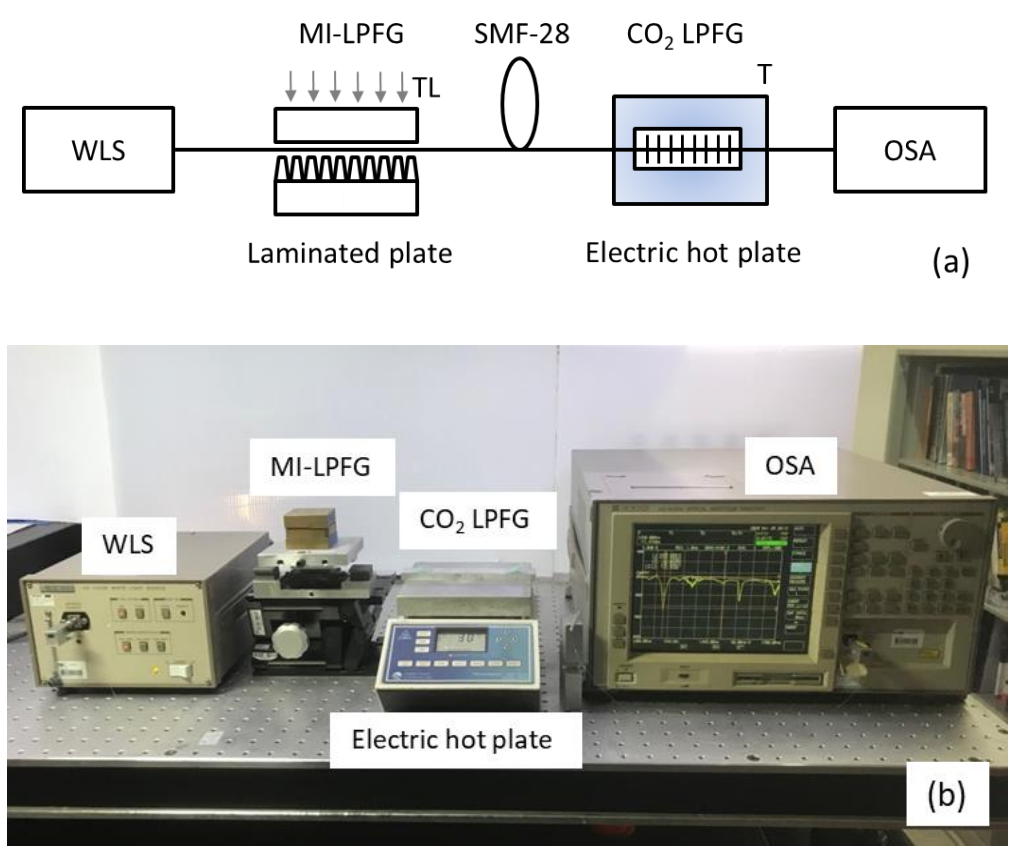

Figure 1. Experimental configuration: (a) schematic and (b) photography.

The MI-LPFG can be achieved when the optical fiber is compressed between a flat aluminum plate and a laminated plate, see Figure $1 \mathrm{~b}$. The laminated plate consisted of a parallel assembling of single-edged utility blades [23]. The laminated plate had a length of approximately $30 \mathrm{~mm}$, an average period of $490 \pm 10 \mu \mathrm{m}$, and an average duty cycle of the refractive-index modulation of 0.2. Figure 2a shows the transmission spectrum of the MI-LPFG when a constant transverse load of $2000 \mathrm{~g}$ is applied between the plates. As can be seen, its spectrum transmission shows a primary rejection band at $1279.3 \mathrm{~nm}$ with a sidelobe at $1338.4 \mathrm{~nm}$ and shallow rejection bands at 1386.0 and $1484.2 \mathrm{~nm}$. The primary rejection band's attenuation depth was $14.4 \mathrm{~dB}$, whereas the attenuation depth for the lateral shallow rejection bands was lower than $1.5 \mathrm{~dB}$. According to the reference spectrum transmission of the MI-LPFG, its average insertion loss is lower than $0.25 \mathrm{~dB}$ for the above 
conditions. It should be noted that the MI-LPFG has no attenuation bands in the spectral range from 1540-1640 nm, although a small portion of light can propagate through the cladding, as can be inferred from the background loss induced by the MI-LPFG in that spectral range.
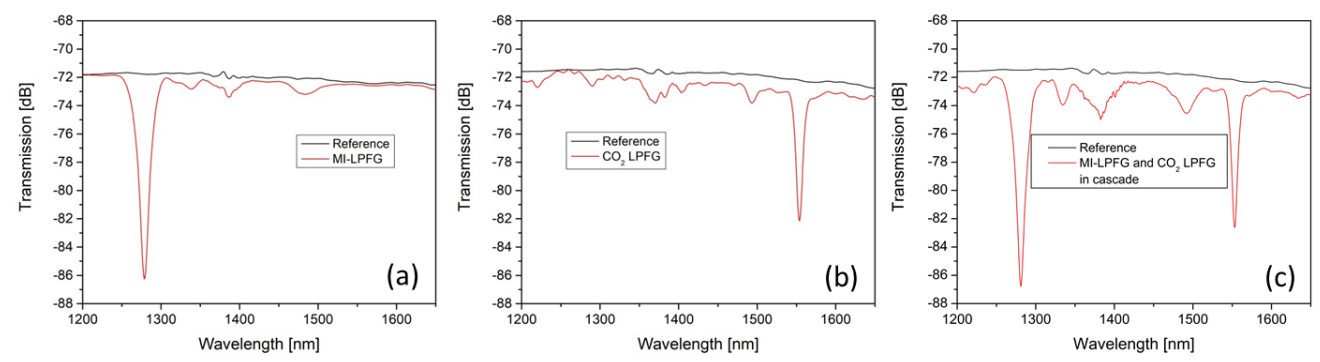

Figure 2. The transmission spectrum of (a) mechanically induced long-period fiber grating (MILPFG), (b) $\mathrm{CO}_{2}$ LPFG, (c) multiplexed MI-LPFG and $\mathrm{CO}_{2}$ LPFG.

On the other hand, the $\mathrm{CO}_{2}$ LPFG was inscribed using a continuous-wave $\mathrm{CO}_{2}$ laser glass processing system (Laser Master LZM-100). It has a length of $37.5 \mathrm{~mm}$ and a period of $0.75 \mathrm{~mm}$. In the inscription process, a fiber section is heated during $120 \mathrm{~ms}$ with a power discharge of $20 \mathrm{~W}$; then, with the same power, the fiber is pulled for $60 \mathrm{~ms}$. In order to have a principal rejection band in the spectral range of $1540-1580 \mathrm{~nm}$, a period of $0.75 \mathrm{~nm}$ was determined empirically based on an extensive experimental study. Figure $2 b$ shows its transmission spectrum. As can be seen, the transmission spectrum displays a primary rejection band at $1553.8 \mathrm{~nm}$ with $9.8 \mathrm{~dB}$ and shallow rejection bands at 1220.2, 1289.7, 1370.8, and $1493.7 \mathrm{~nm}$ with attenuation depths lower than $2.2 \mathrm{~dB}$. According to the reference spectrum transmission, the average insertion loss is lower than $0.85 \mathrm{~dB}$. The insertion loss is due to the scattering produced by the heated points irradiated by the continuous-wave $\mathrm{CO}_{2}$ laser. The $\mathrm{CO}_{2}$ LPFG was fixed on an aluminum holder $(12 \times 2 \times 1 \mathrm{~cm})$ by commercial epoxy putty. The $\mathrm{CO}_{2}$ LPFG was sat on the aluminum holder by pasting its two ends with a physical separation of $10 \mathrm{~cm}$. Then the aluminum holder with the $\mathrm{CO}_{2} \mathrm{LPFG}$ was placed over the electric hot plate, see Figure $1 \mathrm{~b}$. The maximum operating temperature of the epoxy putty was $110^{\circ} \mathrm{C}$. For its part, Figure 2c illustrates the transmission spectrum of the MI-LPFG and the $\mathrm{CO}_{2}$ LPFG in cascade when a constant transverse load of $2000 \mathrm{~g}$ is applied in the MI-LPFG. We can observe the primary rejection bands of the LPFGs and the overlapping of their shallow rejection bands. The insertion loss of the cascaded LPFGs is less than $1.1 \mathrm{~dB}$ regarding the reference transmission spectrum.

\section{Experiment and Results Analysis}

Once the experimental setup was installed, the transverse load on the MI-LPFG was increased from 0 to $2000 \mathrm{~g}$ with increments of $500 \mathrm{~g}$, while the $\mathrm{CO}_{2} \mathrm{LPFG}$ remains unloaded. Both LPFGs in the proofs stayed at room temperature $\left(27 \pm 3{ }^{\circ} \mathrm{C}\right)$. Figure 3 a shows the transmission spectrum evolution of the multiplexed LPFGs when the load on the MI-LPFG increases. As a result, the attenuation depth of the leading rejection band of the MI-LPFG got more profound as the transverse load increased. In contrast, the attenuation depth of the principal rejection band of the $\mathrm{CO}_{2}$ LPFG remains practically unchanged. Figure $3 b, c$ shows the spectrum transmission evolution of the primary rejection bands of the multiplexed LPFGs when the transverse load increases. No wavelength shift is observed in the MILPFG primary rejection band. In contrast, the principal rejection band of the $\mathrm{CO}_{2} \mathrm{LPFG}$ presents a tiny wavelength shift to larger wavelengths that can be practically considered negligible. Figure 4 illustrates the attenuation depth evolution of the primary rejection bands of the multiplexed LPFGs versus the transverse load on the MI-LPFG. The leading rejection band of the MI-LPFG presents a nonlinear increase, while the attenuation depth of the principal rejection band of $\mathrm{CO}_{2}$ LPFG shows a small variation. It is important to note 
that the shallow rejection bands of the MI-LPFG also got deeper when the transverse load increased, but they do not interfere with the primary rejection band of the $\mathrm{CO}_{2} \mathrm{LPFG}$.
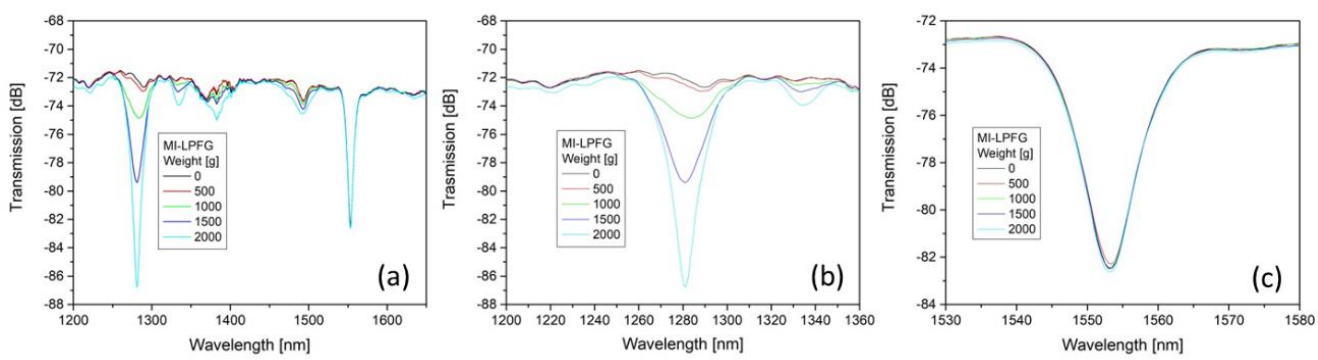

Figure 3. The transmission spectrum of (a) multiplexed LPFGs, (b) MI-LPFG, (c) $\mathrm{CO}_{2}$ LPFG versus applied weight on the MI-LPFG.

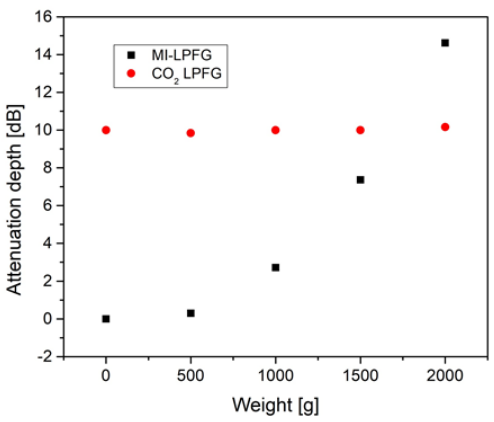

Figure 4. Attenuation depth of the main rejection bands of the MI-LPFG and the $\mathrm{CO}_{2}$ LPFG versus applied weight on the MI-LPFG.

Next, the temperature in the $\mathrm{CO}_{2}$ LPFG was increased from 30 to $110^{\circ} \mathrm{C}$ by steps of $20^{\circ} \mathrm{C}$ using an electric hot plate, whereas the MI-LPFG with a constant transverse load of $2000 \mathrm{~g}$ was kept at room temperature. Figure 5a shows the transmission spectrum evolution of the multiplexed LPFGs when the temperature in the $\mathrm{CO}_{2}$ LPFG was increased. Figure $5 \mathrm{~b}, \mathrm{c}$ shows the transmission spectrum evolution of the primary rejection bands of the multiplexed LPFGs. As can be seen, the rejection band of the $\mathrm{CO}_{2}$ LPFG shifted towards longer wavelengths with a slight decrease in the attenuation depth. Meanwhile, the leading rejection band of the MI-LPFG presents small variations in the attenuation depth and wavelength shift. Figure 6 shows the wavelength shift of the primary rejection bands of multiplexed LPFGs concerning the spectrum transmission of the multiplexed LPFG at $30{ }^{\circ} \mathrm{C}$. The $\mathrm{CO}_{2}$ LPFG principal rejection band shows a linear wavelength shift when the temperature is increased. This rejection band shows a temperature sensitivity of $\sim 50 \mathrm{pm} /{ }^{\circ} \mathrm{C}$, and its R-squared factor of the linear fitting is 0.9989 . On the other hand, the MI-LPFG leading rejection band presented a small oscillating wavelength shift due to the overlapping with the shallow rejection bands at $1289.7 \mathrm{~nm}$ of the $\mathrm{CO}_{2}$ LPFG. Similarly, the attenuation depth of the leading rejection band of the MI-LPFG is slightly altered.
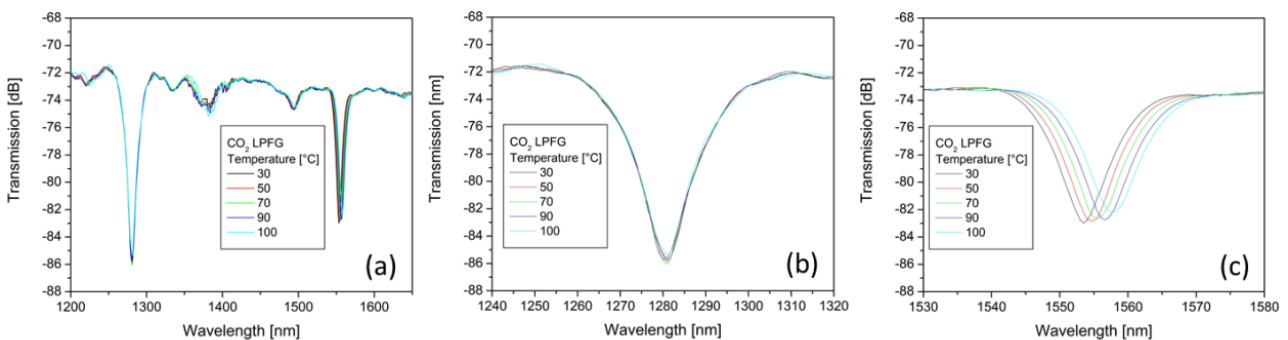

Figure 5. The transmission spectrum of (a) multiplexed LPFGs, (b) MI-LPFG, (c) $\mathrm{CO}_{2}$ LPFG versus applied temperature on the $\mathrm{CO}_{2}$ LPFG. 


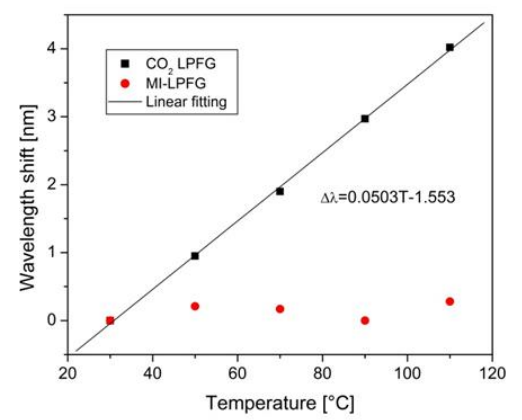

Figure 6. The wavelength shift of the main rejection bands of MI-LPFG and $\mathrm{CO}_{2}$ LPFG versus applied temperature on $\mathrm{CO}_{2}$ LPFG.

Then, the transverse load on the MI-LPFG and the temperature in the $\mathrm{CO}_{2}$ LPFG were simultaneously measured. Thus, the transverse load was increased from 0 to $2000 \mathrm{~g}$ by increments of $500 \mathrm{~g}$ in the MI-LPFG, while the temperature was also increased from 30 to $110^{\circ} \mathrm{C}$ by steps of $20^{\circ} \mathrm{C}$ in the $\mathrm{CO}_{2}$ LPFG. Figure 7a shows the transmission spectrum evolution of the multiplexed LPFGs for these conditions. Figure $7 b, c$ shows the primary rejection bands evolution of the multiplexed LPFGs when the transverse load and the temperature were increased, respectively. Figure 8 a shows the leading rejection band's attenuation depth behavior in the MI-LPFG when the transverse load increases for different temperatures at the $\mathrm{CO}_{2}$ LPFG. The attenuation depth shows a nonlinear increase, similar to the results obtained previously in Figure 4 . On the other hand, Figure $8 \mathrm{~b}$ shows the principal rejection band's wavelength shift in the $\mathrm{CO}_{2} \mathrm{LPFG}$ with respect to spectrum transmission at $30{ }^{\circ} \mathrm{C}$ for the above conditions. The principal rejection band's center wavelength in the $\mathrm{CO}_{2}$ LPFG shows a linear wavelength shift towards longer wavelengths. The rejection band shows a temperature sensitivity of $\sim 50 \mathrm{pm} /{ }^{\circ} \mathrm{C}$, and its R-squared factor of the linear fitting was 0.9986 .
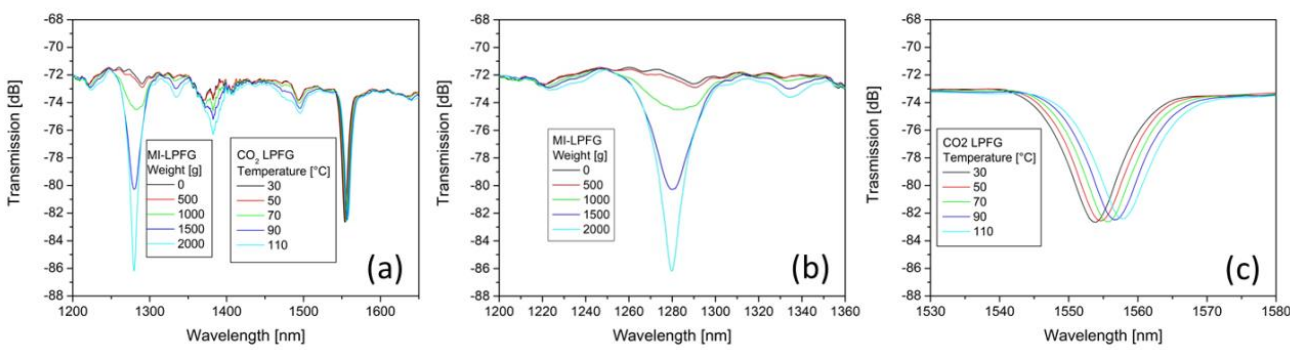

Figure 7. The transmission spectrum of (a) multiplexed LPFGs, (b) MI-LPFG, (c) $\mathrm{CO}_{2}$ LPFG versus applied transverse load on MI-LPFG and temperature on the $\mathrm{CO}_{2}$ LPFG, simultaneously.
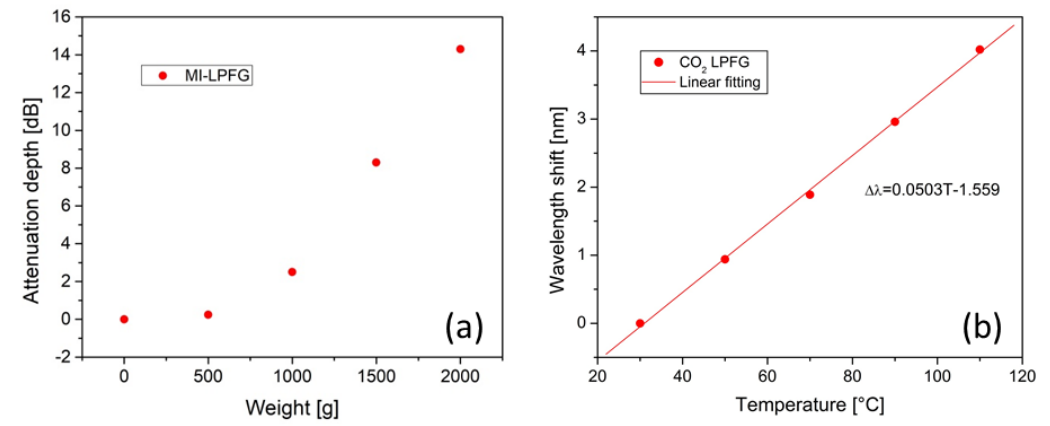

Figure 8. (a) Attenuation depth of MI-LPFG, and (b) wavelength shift of the $\mathrm{CO}_{2}$ LPFG for the simultaneous measurement of transverse load and temperature, respectively.

The MI-LPFG displays a leading rejection band at $1280 \pm 1 \mathrm{~nm}$, while the $\mathrm{CO}_{2} \mathrm{LPFG}$ presents a principal rejection band at $1553.80 \mathrm{~nm}$ at room temperature $\left(27^{\circ} \mathrm{C}\right)$. The wave- 
length separation between the primary rejection bands allows the CWDM of LPFGs with low cladding-mode crosstalk. When the transverse load in the MI-LPFG was increased from 0-2000 g, the principal rejection band of the $\mathrm{CO}_{2}$ LPFG underwent attenuation depth variations lower than $\pm 0.2 \mathrm{~dB}$ and a wavelength shift lower than $\pm 0.2 \mathrm{~nm}$ with respect to the initial spectrum transmission. We assume that these random variations are due to the white light source output power stability combined with the insertion loss induced by the MILPFG. Note that the MI-LPFG transverse load sensitivity was obtained at a constant room temperature. However, it is well known that attenuation depth and the central wavelength location of the rejection bands are influenced by the temperature on the MI-LPFGs [28]. It had been observed that with a temperature increase on the MI-LPFGs, the rejection bands shift to longer wavelengths, and their attenuation depth partially decreases. In this sense, to include the effect of the temperature on the MI-LPFG response, the transverse load sensitivity, and the wavelength shifting sensitivity of the principal rejection band can be calibrated at different temperatures. On the other hand, when the temperature in the $\mathrm{CO}_{2}$ LPFG was increased from 30 to $110^{\circ} \mathrm{C}$, the leading rejection band in the MI-LPFG experienced an attenuation depth variation lower than $\pm 0.4 \mathrm{~dB}$ and a wavelength shift lower than $\pm 0.3 \mathrm{~nm}$ with respect to the initial spectrum transmission. We assume that these variations are also due to the white light source output power stability and the overlapping between the leading rejection band in the MI-LPFG and the $\mathrm{CO}_{2}$ LPFG shallow rejection band at $1289.7 \mathrm{~nm}$. In the last case, increasing the separation between the LPFGs can significantly reduce the overlapping effect since cladding light will be attenuated by the high index polymer coating of the optical fiber section between LPFG. On the other side, the random variations of the power transmission spectrum introduced by the white light source can be eliminated using a broadband light source by combining two superluminescent diodes at 1280 and $1550 \mathrm{~nm}$.

The above results were replicated when we simultaneously measured the transverse load and the temperature in the multiplexed LPFGs, respectively. Figure 9a displays a comparison between the individual and simultaneous measurement of the attenuation depth in the MI-LPFG. As can be seen, except for the attenuation depth corresponding to $1500 \mathrm{~g}$, the remainder attenuation depth points preserve a close correlation. This difference at $1500 \mathrm{~g}$ can be due to the repeatability of the MI-LPFG. Meanwhile, Figure $9 \mathrm{~b}$ illustrates a comparison between the wavelength shift in the $\mathrm{CO}_{2}$ LPFG for the individual and simultaneous temperature measurement, where one can observe a close correlation between individual and simultaneous measurements of the temperature. According to these results, the multiplexed LPFGs operate with low cladding-mode crosstalk. The experimental results demonstrate the simultaneous measurement of transverse load and temperature by the multiplexed LPFGs. The current multiplexed LPFGs arrangement uses an MILPFG; however, it is possible to produce LPFGs with a primary rejection band by other inscription methods such as electric arc discharge and femtosecond laser irradiation [25-27]. These LPFGs may allow more flexible schemes of distributed sensing applications based on multiplexed LPFGs in cascade.
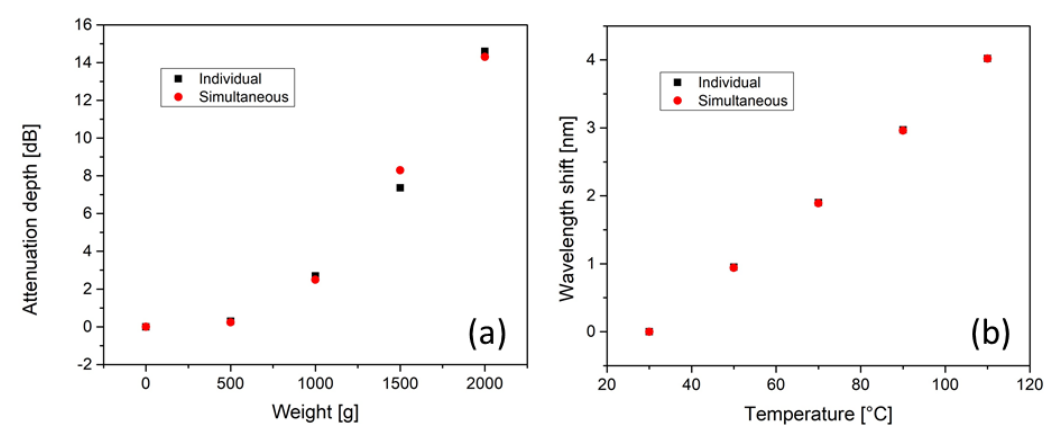

Figure 9. Individual and simultaneous measurement of (a) attenuation depth in the MI-LPFG and (b) wavelength shift in the $\mathrm{CO}_{2}$ LPFG. 


\section{Conclusions}

The simultaneous measurement of transverse load and temperature using two multiplexed long-period fiber gratings has been demonstrated experimentally in this work. We have used an MI-LPFG with a $\mathrm{CO}_{2}$ LPFG connected in cascade to measure the transverse load and the temperature, respectively. The experimental results show that the transverse load and temperature measurements show low cladding-mode crosstalk between the multiplexed LPFGs. In fact, the cladding-mode crosstalk can be canceled by increasing the length of the fiber between the gratings. The low or absence of cladding-modes crosstalk, simplify the interrogation method since only changes in transmission need to be measured. It is well known that distributed sensing applications are still a trend in the development of optical fiber sensors based on multiplexed LPFGs. In this regard, we propose the CWDM of long-period fiber gratings with a leading rejection band to determine multiple parameters simultaneously. To our best knowledge, this is the first time that coarse multiplexing of LPFGs has been reported for multiple parameter sensing using LPFGs with a leading rejection band. The new concept of multiplexed LPFGs using MI-LPFG with only one leading rejection band can facilitate the CWDM of several LPFGs in cascade. This technique can improve the implementation of fiber optic distributed sensing systems based on the wavelength-division multiplexing of LPFGs.

Author Contributions: Conceptualization, I.T.-G.; methodology, A.M.-R. and D.E.C.-H.; validation, G.A.-S. and G.S.-D.; formal analysis, D.E.C.-H.; investigation, G.A.-S. and G.S.-D.; writingoriginal draft preparation, I.T.-G. and A.M.-R.; writing-review and editing, all authors; supervision, A.M.-R.; project administration, I.T.-G. All authors have read and agreed to the published version of the manuscript.

Funding: This research received no external funding.

Conflicts of Interest: The authors declare no conflict of interest.

\section{References}

1. Chiang, K.S.; Liu, Q. Long-period grating devices for application in optical communications. In Proceedings of the 5th ICOCN, Chengdu, China, 23-27 September 2006; pp. 128-133.

2. Krčmařík, D.; Kulishov, M.; Slavík, R. Long-period fiber gratings in active fibers. In Current Trends in Short and Long-Period Fiber Gratings; Cuadrado-Laborde, C., Ed.; InTech: Rijeka, Croatia, 2013; pp. 87-104.

3. Bhatia, V. Applications of long-period gratings to single and multi-parameter sensing. Opt. Express 1999, 4, 457-466. [CrossRef] [PubMed]

4. Rao, Y.J.; Wang, Y.P.; Ran, Z.L.; Zhu, T. Novel fiber-optic sensors based on long-period fiber grating written by high-frequency $\mathrm{CO}_{2}$ laser pulses. J. Lightwave Technol. 2003, 21, 1320-1327.

5. Korposh, S.; James, S.; Tatam, R.; Lee, S.W. Optical fibre long-period gratings functionalized with nano-assembled thin films: Approaches to chemical sensing. In Current Trends in Short and Long-Period Fiber Gratings; Cuadrado-Laborde, C., Ed.; InTech: Rijeka, Croatia, 2013; pp. 63-83.

6. Zhao, X.W.; Wang, Q. Mini review: Recent advances in long period fiber grating biological and chemical sensors. Instrum. Sci. Technol. 2019, 47, 40-169. [CrossRef]

7. Vengsarkar, A.M.; Lemaire, P.J.; Judkins, J.B.; Bhatia, V.; Erdogan, T.; Sipe, J.E. Long-period fiber gratings as band-rejection filters. J. Lightwave Technol. 1996, 14, 58-65. [CrossRef]

8. Enomoto, T.; Shigehara, M.; Ishikawa, S.; Danzuka, T.; Kanamori, H. Long-period fiber grating in a pure-silica-core fiber written by residual stress relaxation. In Proceedings of the OFC'98. Optical Fiber Communication Conference and Exhibit. Technical Digest, Conference Edition, 1998 OSA Technical Digest Series, San Jose, CA, USA, $22-27$ February 1998; Volume 2, pp. 277-278.

9. Davis, D.D.; Gaylord, T.K.; Glytsis, E.N.; Kosinski, S.G.; Mettler, S.C.; Vengsarkar, A.M. Long-period fibre grating fabrication with focused CO2 laser pulses. Electron. Lett. 1998, 34, 302-303. [CrossRef]

10. Kondo, Y.; Nouchi, K.; Mitsuyu, T.; Watanabe, M.; Kazansky, P.G.; Hirao, K. Fabrication of long-period fiber gratings by focused irradiation of infrared femtosecond laser pulses. Opt. Lett. 1999, 24, 646-648. [CrossRef]

11. Savin, S.; Digonnet, M.J.F.; Kino, G.S.; Shaw, H.J. Tunable mechanically induced long-period fiber gratings. Opt. Lett. 2000, 25, 710-712. [CrossRef]

12. Fu, C.; Liu, S.; Bai, Z.; He, J.; Liao, C.; Wang, Y.; Li, Z.; Zhang, Y.; Yang, K.; Yu, B.; et al. Orbital angular momentum mode converter based on helical long period fiber Grating Inscribed by Hydrogen-Oxygen lame. J. Lightwave Technol. 2018, 36, 1683-1688. [CrossRef] 
13. Fujimaki, M.; Ohki, Y.; Brebner, J.L.; Roorda, S. Fabrication of long-period optical fiber gratings by use of ion implantation. Opt. Lett. 2000, 25, 88-89. [CrossRef]

14. Dos Santos, P.S.S.; Jorge, P.A.S.; de Almeida, J.M.M.M.; Coelho, L. Low-cost interrogation system for long-period fiber gratings applied to remote sensing. Sensors 2019, 19, 1500. [CrossRef]

15. Gu, X.J. Wavelength-division multiplexing isolation fiber filter and light source using cascaded long-period fiber gratings. Opt. Lett. 1998, 23, 509-510. [CrossRef] [PubMed]

16. Murphy, R.P.; James, S.W.; Tatam, R.P. Multiplexing of fiber-optic long-period grating-based interferometric sensors. J. Lightwave Technol. 2007, 25, 825-829. [CrossRef]

17. Huang, Q.; Chen, H. Multi-parameter optochemical sensing based on coated cascaded long-period fiber gratings and frequency division multiplexing. Optik 2017, 132, 348-355. [CrossRef]

18. Bhatia, V.; Campbell, D.; Claus, R.O.; Vengsarkar, A.M. Simultaneous strain and temperature measurement with long-period gratings. Opt. Lett. 1997, 22, 648-650. [CrossRef] [PubMed]

19. Yokota, M.; Oka, H.; Yoshino, T. Mechanically induced long period fiber grating and its application for distributed sensing. In Proceedings of the 2002 15th Optical Fiber Sensors Conference Technical Digest, Portland, OR, USA, 6-10 May 2002; pp. 135-138.

20. Eftimov, T.; Bock, W.; Mikulic, P.; Nikolova, K. Multiplexed long period gratings with differential Interrogation. 16 ISCMP: Progress in Solid State and Molecular Electronics, Ionics and Photonics. J. Phys. Conf. Ser. 2010, 253, 012023. [CrossRef]

21. Zhan, Y.; Gu, K.; Wu, H.; Luo, F. A combined long period fiber grating multi-parameter sensor. Sens. Rev. 2013, 33, 220-227. [CrossRef]

22. Hromadka, J.; Korposh, S.; Partridge, M.C.; James, S.W.; Davis, F.; Crump, D.; Tatam, R.P. Multi-parameter measurements using optical fibre long period gratings for indoor air quality monitoring. Sens. Actuat. B Chem. 2017, 244, 217-225. [CrossRef]

23. Torres-Gómez, I.; Ceballos-Herrera, D.E.; Salas-Alcantara, K.M. Mechanically-induced long-Period fiber gratings using laminated plates. Sensors 2020, 20, 2582. [CrossRef]

24. Rego, G.; Fernandes, J.R.A.; Santos, J.L.; Salgado, H.M.; Marques, P.V.S. New technique to mechanically induce long-period fibre gratings. Opt. Commun. 2003, 220, 111-118. [CrossRef]

25. Rego, G.; Okhotnikov, O.; Dianov, E.; Sulimov, V. High-temperature stability of long-period fiber gratings produced using an electric arc. J. Lightwave Technol. 2001, 19, 1574-1579. [CrossRef]

26. Nam, S.H.; Zhan, C.; Lee, J.; Hahn, C.; Reichard, K.; Ruffin, P.; Deng, K.L.; Yin, S. Bend-insensitive ultra short long-period gratings by the electric arc method and their applications to harsh environment sensing and communication. Opt. Express 2005, 13, 731-737. [CrossRef] [PubMed]

27. Sun, X.; Huang, P.; Zhao, J.; Wei, L.; Zhang, N.; Kuang, D.; Zhu, X. Characteristic control of long period fiber grating (LPFG) fabricated by infrared femtosecond laser. Front. Optoelectron. 2012, 5, 334-340. [CrossRef]

28. García-de-la-Rosa, L.A.; Torres-Gómez, I.; Martínez-Ríos, A.; Monzón-Hernández, D. Temperature impact on mechanically induced long-period fiber gratings. Opt. Laser Eng. 2011, 49, 714-717. [CrossRef] 